\title{
EVOLUÇÃO SEDIMENTAR DO SUPERGRUPO MINAS: 500 MA. DE REGISTRO GEOLÓGICO NO QUADRILÁTERO FERRÍFERO, MINAS GERAIS, BRASIL
}

\author{
Friedrich E. Renger (*), Carlos M. Noce (*), \\ Antônio W. Romano (**) \& Nuno Machado (***)
}

\begin{abstract}
It is now possible to bracket the age of the Minas Supergroup with reasonable precision between about 2580 Ma. (base of the Moeda Formation) and 2050 Ma. (top of the Sabará Formation) on the basis of precise zircon U-Pb age determinations from both granitic rocks of the basement and detrital zircons from quartzites and graywackes of the Proterozoic metasedimentary sequences of the Quadrilátero Ferrífero.

Three major unconformities subdivide the stratigraphic column into three sequences. The first sequence comprises the Moeda, Batatal, Cauê and Gandarela Formations from 2580 to 2400 Ma.. The second sequence comprises the Cercadinho, Fecho do Funil, Taboões and Barreiro Formations (the Piracicaba Group) dated at 2400 to $2150 \mathrm{Ma}$.. The third sequence contains only the synorogenic sediments of the Sabará Formation, deposited during the Transamazonian Event between 2150 and 2050 Ma.. This event folded and metamorphosed the Minas Supergroup for the first time.

The Sabará Formation of the Piracicaba Group has very different sedimentological characteristics from the other formations of this group and is exceptionally thick (about $3500 \mathrm{~m}$ ), we therefore propose to upgrade it to the rank of a Group.

Zircon age histograms of the Moeda quartzite (sample QF-1) and Sabará graywacke are similar, indicating a common Archean source, i.e. the Belo Horizonte Complex north of the Quadrilátero Ferrífero. This implies that sedimentation of the Minas Supergroup in the western Quadrilátero Ferrífero is autochthonous.

Periods of carbonate and Iron Formation platform sedimentation (Cauê, Gandarela and partly Fecho do Funil Formations) coincide with minor frequency of age plots of detrital zircons, indicating also a stable tectonic environment.

Comparison of the Minas Supergroup with the Transvaal Sequence of South Africa reveals correspondence not only in age but also in thickness, position of the major unconformities, lithological compositions and in the position of gold and pyrite bearing quartz-pebble conglomerates.

Palavras-chave: Quadrilátero Ferrífero, Supergrupo Minas, Transvaal Sequence, Geocronologia, Litoestratigrafia, Grupo Sabará, Paleoproterozóico
\end{abstract}

\section{INTRODUÇÃO}

A integração dos dados geocronológicos disponíveis para o Quadrilátero Ferrífero, tanto para as seqüências sedimentares neo-arqueanas a paleoproterozóicas, como para o seu embasamento, permite deduzir, com razoável precisão, os intervalos de sedimentação destas sequiências. O destaque maior deste trabalho é dado para o Supergrupo Minas, buscando-se estabelecer a correlação entre eventos tectônicos de maior soerguimento ou subsidência da bacia e o registro sedimentar correspondente. Adicionalmente, são feitas inferências sobre as possíveis áreas-fonte para a sedimentação detrítica. Propõe-se também uma redefinição do Supergrupo Minas, desmembrando-se dele a Formação Sabará do Grupo Piracicaba. Considerando suas particularidades sedimentológicas, totalmente distintas das outras formações do Grupo Piracicaba, bem como sua grande espessura, a Formação Sabará é elevada à categoria de grupo, no topo do Supergrupo Minas. Proposição inicial, neste sentido, já havia sido apresentada por A.L.M. Barbosa em 1968.

Trabalhos de geocronologia no Quadrilátero Ferrífero têm enfatizado a datação dos eventos magmáticos e/ou metamórficos (Cordani et al. 1980,
Teixeira 1985, Machado et al. 1992, Teixeira \& Figueiredo 1991, Carneiro et al. 1993). A datação direta de rochas sedimentares do Supergrupo Minas (Babinski et al. 1991 e 1993), somada a um expressivo número de idades de zircões detríticos obtidos por Machado $e t$ al. (1993), tornaram possível a correlação dos eventos sedimentares com os demais eventos geológicos e seu posicionamento na escala de tempo. As idades de zircões detríticos são idades mínimas $\left({ }^{207} \mathrm{~Pb} /{ }^{206} \mathrm{~Pb}\right)$, obtidas pela técnica de LP-ICPMS [Laser ProbeInductively Coupled Plasma Mass Spectrography] (Feng et al. 1993).

\section{O ACERVO GEOCRONOLÓGICO}

\section{Complexos Granito-gnáissicos}

Para os complexos granito-gnáissicos do sudeste do Cráton do São Francisco, que formam o embasamento arqueano do Quadrilátero Ferrífero e seus arredores (fig. 1), existe um acervo de datações $\mathrm{U}-\mathrm{Pb}$ que evidencia um longo período evolutivo, entre 3200 e 2600 Ma. (Machado \& Noce 1993). Entretanto, os principais eventos de geração ou retrabalhamento desta crosta arqueana ocorreram no período de 2900 a 2700 Ma., como mostra a tabela 1. 


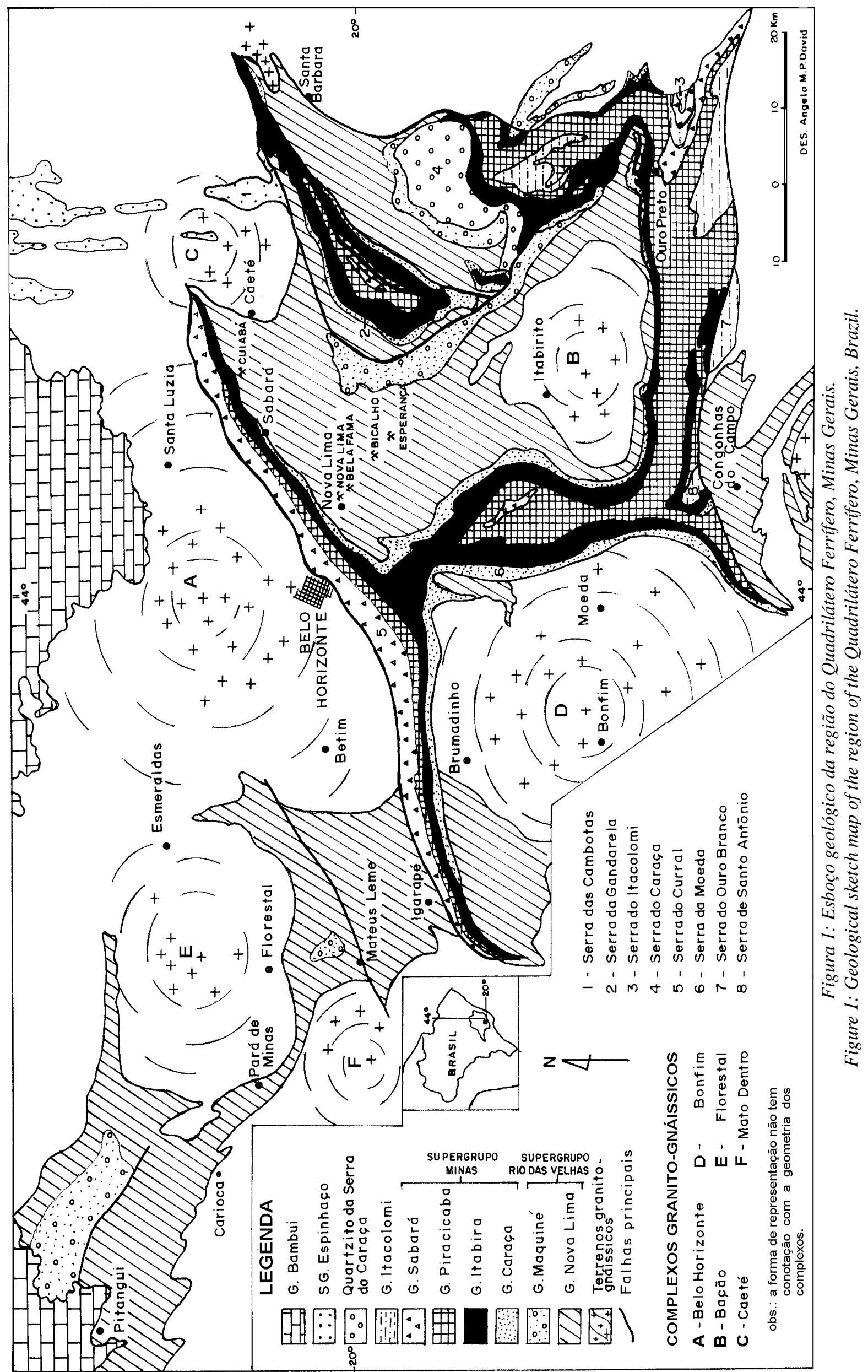




\begin{tabular}{|l|l|l|l|}
\hline \multicolumn{1}{|c|}{ Complexo } & \multicolumn{1}{c|}{ Litotipo } & Idade (Ma) & \multicolumn{1}{c|}{ Autor } \\
\hline Florestal & granodiorito & $2593+10 /-19^{*}$ & Romano 1989 \\
\hline $\begin{array}{l}\text { Salto do } \\
\text { Paraopeba }\end{array}$ & granito & $2612 \pm 5^{*}$ & Noce 1994 \\
\hline Bonfim & granito & $2703+24 /-20^{*}$ & Machado \& Carneiro 1992 \\
\hline Belo Horizonte & granito & $2712+5 /-4^{*}$ & Machado \& Noce 1993 \\
Bonfim & granito & $2721 \pm 3^{*}$ & Machado et al. 1992 \\
\hline Mato Dentro & granito & $2755+14 /-13^{*}$ & Romano 1989 \\
\hline Bonfim & gnaisse/migmatito & $2772 \pm 6^{* *}$ & Machado \& Carneiro 1992 \\
\hline Caeté & granodiorito & $2776+7 /-6^{*}$ & Machado et al. 1992 \\
\hline Bonfim & tonalito & $2780+3 /-2^{*}$ & Machado \& Carneiro 1992 \\
\hline Bação & granito & $2820^{* * *}$ & Delhal \& Demaiffe 1985 \\
\hline Belo Horizonte & gnaisse/migmatito & $2860+14 /-10^{* *}$ & Noce 1994 \\
\hline
\end{tabular}

Tabela 1: Datações U-Pb em zircão para os complexos granito-gnáissicos do embasamento arqueano do Quadrilátero Ferrífero ( ${ }^{*}$ - idades de cristalização; ${ }^{* *}$ - idades de retrabalhamento/metamorfismo; *** - idade mínima).

O principal período de remobilização destes complexos ocorreu no Evento Transamazônico, como demonstrado por diversas datações $\mathrm{Rb}$-Sr (Teixeira 1985, Teixeira et al. 1987, Belo de Oliveira \& Teixeira 1990). Com base em datações U-Pb, Machado \& Noce (1993) afirmam que o ápice deste evento deve ter acontecido no período entre 2125-2040 Ma.. Adicionalmente, estes mesmos autores sugerem a ocorrência de um evento paleoproterozóico mais antigo, a cerca de 2400 Ma.. Besang et al. (1977) obtiveram idades $\mathrm{Rb}$-Sr nesta mesma faixa, na região a noroeste do Quadrilátero Ferrífero. A tabela 2 apresenta algumas das datações $\mathrm{Rb}$-Sr e U-Pb paleoproterozóicas registradas em rochas dos complexos granito-gnáissicos.

\section{Supergrupo Rio das Velhas}

Existem poucas datações para as rochas sedimentares ou vulcânicas do Arqueano. Machado et al. (1992) determinaram idades $\mathrm{U}-\mathrm{Pb}$ em torno de $2776 \mathrm{Ma}$. para rochas efusivas ácidas do Grupo Nova Lima na região de Piedade de Paraopeba, oeste do Quadrilátero Ferrífero e na região de Caeté, nordeste do Quadrilátero Ferrífero. Não existem datações, até o presente, para o Grupo Maquiné.

Thorpe et al. (1984) analisaram, pelo método $\mathrm{Pb} /$ $\mathrm{Pb}$, galenas de diversas minas do distrito aurífero de Nova Lima (tabela 3). A idade mais antiga, arqueana, é atribuida pelos autores à época de formação da galena, enquanto as demais são relacionadas a remobilizações durante eventos tectono-metamórficos do final do Arqueano (2575-2495 Ma.) e tardi-transamazônico (1935 Ma.). É interessante notar que estas galenas não apresentam nenhum registro do Evento Brasiliano.

\section{Supergrupo Minas, Grupo Itacolomi e Supergrupo Espinhaço}

As datações do Supergrupo Minas, ainda que em número restrito, permitem balizar a idade desta unidade,

\begin{tabular}{|l|l|l|l|l|}
\hline \multicolumn{1}{|c|}{ Complexo } & \multicolumn{1}{c|}{ Litotipo } & Idade (Ma) & Método & \multicolumn{1}{c|}{ Autor } \\
\hline Acaiaca & gnaisse & $2009 \pm 219$ & $\mathrm{Rb}-\mathrm{Sr}$ & Teixeira et al. 1987 \\
\hline Rio Casca & gnaisse & $2064 \pm 213$ & $\mathrm{Rb}-\mathrm{Sr}$ & Teixeira et al. 1987 \\
\hline Belo Horizonte & gnaisse/migmatito & $2041 \pm 5$ & $\mathrm{U}-\mathrm{Pb}$ & Noce 1994 \\
\hline Bação & anfibolito & $2059 \pm 6$ & $\mathrm{U}-\mathrm{Pb}$ & Machado et al. 1992 \\
\hline Caeté & milonito-gnaisse & $2130 \pm 101$ & $\mathrm{Rb}-\mathrm{Sr}$ & Belo de Oliveira \& Teixeira, 1990 \\
\hline Carioca & gnaisse & $2410 \pm 90$ & $\mathrm{Rb}-\mathrm{Sr}$ & Besang et al. 1977 \\
\hline Pará de Minas & granodiorito & $2433 \pm 55$ & $\mathrm{Rb}-\mathrm{Sr}$ & Besang et al. 1977 \\
\hline
\end{tabular}

Tabela 2: Datações de eventos metamórficos (retrabalhamento) do Paleoproterozóico no embasamento arqueano do Quadrilátero Ferrífero e adjacências. Idades isocrônicas $\mathrm{Rb}$-Sr em rocha total e idades 


\begin{tabular}{|l|c|c|}
\hline \multicolumn{1}{|c|}{ Mina } & Idade (Ma) & Interpretação \\
\hline Bela Fama & 1935 & idade de remobilização \\
\hline Bicalho & 2495 & ídem \\
\hline Cuiabá & 2510 & ídem \\
\hline Esperança & 2550 & ídem \\
\hline Bicalho & 2575 & ídem \\
\hline Bela Fama & 2710 & idade de formação \\
\hline
\end{tabular}

Tabela 3: Datações Pb/Pb (idade modelo) em galenas de minas de ouro do Distrito de Nova Lima, Quadrilátero Ferrifero (dados de Thorpe et al. 1984).

bem como identificar certos eventos sedimentológicos. Machado et al. (1993) determinaram idades de zircões detríticos em duas amostras de quartzito da parte inferior da Formação Moeda (base da Unidade I), a formação basal do Supergrupo Minas. As amostras são provenientes da Serra da Moeda, aba oeste do sinclinal homônimo, e os resultados encontram-se na tabela 4 . Todos os zircões analisados são de idade arqueana, os mais novos com cerca de 2650 Ma.. Este valor representa a idade máxima para o início da deposição do Supergrupo Minas. A grande maioria dos zircões exibe idades dentro de um intervalo de cerca de 200 Ma., indicando certa homogeneidade geocronológica, ou mesmo geológica, para as áreas-fonte dos sedimentos da Formação Moeda.

\begin{tabular}{|l|c|r|l|}
\hline Amostra & $\begin{array}{c}\mathbf{N}^{\mathbf{0}} \text { de } \\
\text { datações }\end{array}$ & $\begin{array}{c}\text { Intervalo } \\
\text { de idade (Ma) }\end{array}$ & Observações \\
\hline M-88-10 & 17 & $2650-2800$ & \\
QF-1 & 15 & $2780-2990$ & um valor \\
& & & errático a 3220 \\
\hline
\end{tabular}

Tabela 4: Idades ${ }^{207} \mathrm{~Pb}{ }^{206} \mathrm{~Pb}$ em zircões detríticos de quartzitos da base da Formação Moeda, provenientes da

Serra da Moeda (dados de Machado et al. 1993).

Babinski et al. (1991, 1993) dataram os dolomitos estromatolíticos do topo da Formação Gandarela, pelo método $\mathrm{Pb} / \mathrm{Pb}$, obtendo idade de $2420 \pm 19 \mathrm{Ma}$.. A amostra é proveniente do centro do Sinclinal Gandarela, região leste do Quadrilátero Ferrífero. Devido à preservação de estruturas orgânicas, aliado à ausência de evidências de deformação, esta foi considerada como idade de deposição da unidade. Os mesmos autores dataram uma amostra de rocha carbonática do Grupo
Piracicaba (dolomito da Formação Fecho do Funil), obtendo 2050 \pm 230 Ma.. Este resultado é interpretado como resultante da pertubação do sistema isotópico durante o metamorfismo associado ao Evento Transamazônico.

Amostras dos grupos Sabará, Itacolomi e Supergrupo Espinhaço tiveram zircões detríticos datados (Machado et al. 1993). Ao contrário do que ocorre com as amostras da Formação Moeda, estas unidades incluem zircões detríticos de idade paleoproterozóica. No conjunto, as idades variam entre 3100 e 2100 Ma. (tabela 5). Esta grande dispersão pode ser explicada pelo soerguimento de novas áreas-fonte com grande diversidade geológica e geocronológica.

\section{CONSIDERAÇÕES SOBRE A EVOLUÇÃO SEDIMENTOLÓGICA DO SUPERGRUPO MINAS}

A sedimentação da seqüência inicial do Supergrupo Minas (Fig. 2 e 3) está balizada entre 2650 Ma., idade mais nova dos zircões detríticos do quartzito Moeda, e 2420 Ma., idade de sedimentação do topo da Formação Gandarela. Babinski et al. (1993) sugerem a idade de 2520 Ma. para o início da sedimentação da Formação Cauê (formação ferrífera bandada), baseado em uma estimativa da taxa de sedimentação da ordem de $50 \mathrm{~m} /$ Ma. para as formações Gandarela e Cauê. Extrapolando este cálculo para as formações sotopostas à Formação Cauê (formações Batatal e Moeda), obteríamos a idade de 2620 Ma. para a base do Supergrupo Minas.

Por outro lado, a deposição da Formação Moeda deve ser da mesma idade ou mais jovem que os últimos eventos de granitogênese arqueana, representada pelo Granito Salto do Paraopeba (2612 \pm 5 Ma., Noce 1994)

\begin{tabular}{|c|c|c|c|c|}
\hline Amostra & $\begin{array}{c}\text { Número de } \\
\text { datações }\end{array}$ & Localidade & $\begin{array}{c}\text { Intervalo de idade } \\
\text { (Ma) }\end{array}$ & Unidade \\
\hline SAB & 45 & Igarapé & $2120-3120$ & Grupo Sabará \\
\hline ITAC & 11 & Ouro Preto & $2180-3180$ & Grupo Itacolomi \\
\hline N-91-16 & 49 & Serra das Cambotas & $2260-2970$ & Supergrupo Espinhaço \\
\hline
\end{tabular}

Tabela 5: Idades ${ }^{207} \mathrm{~Pb} /{ }^{206} \mathrm{~Pb}$ em zircões detríticos de grauvaca do Grupo Sabará e quartzitos dos Grupos Itacolomi e Supergrupo Espinhaço (dados de Machado et al. 1993). 
e pelo Granito de Florestal (2593+18/-19 Ma., Romano 1989). Assim, propomos uma idade entre 2590 e 2560 Ma. para a base desta unidade. Esta idade marcaria o início da implantação das protobacias Minas sobre uma plataforma arqueana recém consolidada.

As idades dos zircões detríticos da Formação Moeda, entre 2650 e 3000 Ma., enquadram-se na faixa de idades dos complexos granito-gnáissicos do embasamento arqueano do Quadrilátero Ferrífero (vide Tabela 1 e Figura 2). Este fato sugere que a recém instalada protobacia Moeda seria alimentada pela erosão dos domos gnáissicos adjacentes, em processo de soerguimento. No aspecto paleogeográfico, existiam escarpas de falha por exemplo na extremidade norte da Serra da Moeda, que foram áreas-fonte de seixos de efusivas ácidas, filito e clorita-xisto do conglomerado basal da Formação Moeda. A proveniência destes seixos deve ser o Grupo Nova Lima, situado imediatamente a oeste, onde ocorrem estes mesmos litotipos (Noce et al. 1992).

As duas amostras do quartzito Moeda estão separadas por pequeno intervalo estratigráfico, mas os zircões detríticos exibem faixas de idades distintas e sem superposição (vide Figura 2). Isso implica em um remodelamento da paleodrenagem entre a deposição das duas amostras, refletindo duas bacias fluviais drenando áreas-fonte distintas. A área-fonte da amostra M-88-10, que exibe idades de zircões detríticos entre 2650 e 2800 Ma., devia se situar a oeste, no Complexo Bonfim, o qual apresenta o mesmo padrão geocronológico (Machado \& Carneiro 1992). A faixa de idades da outra amostra (QF-1), de 2800 a 3000 Ma., aponta para uma proveniência diferente. No Sinclinal Moeda, a maioria dos registros sedimentológicos indicativos de paleogeografia, como a dimuinuição no tamanho dos seixos de conglomerados e medidas de estratificação cruzada, fornece um vetor de paleotransporte para SE ou S (Wallace 1965, Villaça 1981, Renger et al. 1993). Portanto, a área-fonte para a segunda amostra devia estar no Complexo Belo Horizonte, essencialmente constituido por gnaisses mais antigos que $2800 \mathrm{Ma}$. (Noce 1994).

A Formação Moeda mostra recorrência de sedimentação conglomerática no topo, o que pode ser interpretado como um reflexo sedimentológico de pertubações tectônicas da bacia. Um indício geocronológico destes eventos é encontrado nas datações de remobilização de galenas, entre 2575 e 2495 Ma. (Thorpe et al. 1984) A recristalização de galena pode ser provocada por deformação de baixa magnitude e não exige altas temperaturas (Ramdohr 1960). A correlação das idades destas galenas com a sedimentação conglomerática na Formação Moeda é apresentada na Figura 2. Trata-se de uma correlação apenas tentativa, em função dos erros elevados no cálculo destas idades.

No intervalo de 2500 a 2420 Ma. (80 Ma.) não foi descoberto registro geocronológico, nem de zircões detríticos. Este intervalo corresponde à deposição dos sedimentos pelíticos e químicos das formações Batatal, Cauê e Gandarela. Segundo Barbosa (1979): "O Grupo Itabira foi depositada após peneplanação completa da área de abastecimento. A condição reinante era de grande estabilidade tectônica e uniformidade climática."

Entre 2400 e 2300 Ma. verifica-se um certo acúmulo nas datações de zircões detríticos dos grupos Sabará e Itacolomi e do Supergrupo Espinhaço. Nenhum evento magmático desta idade é conhecido até o presente, mas a sedimentação do topo da Formação Gandarela (Babinski et al. 1993) ocorreu neste período. Esta unidade e aquela sobreposta (Formação Cercadinho) estão separadas por discordância erosiva, sendo que a Formação Cercadinho exibe conglomerado basal e horizontes de conglomerado intraformacional, com seixos de itabirito e dolomito (Dorr 1969). A sedimentação da Formação Cercadinho marca profundo remodelamento da bacia Minas, fato este documentado pela emersão de parte da sequiência do Grupo Itabira, sua erosão e redeposição em forma de seixos. Em conseqüência, a Formação Cercadinho encerra o registro sedimentológico de um novo período de pertubação tectônica da bacia, possivelmente iniciado por volta de 2400 Ma.. Rochas magmáticas associadas a este evento, ainda não identificadas ou já erodidas, constituiriam a fonte provável dos zircões desta idade, já encontrados nas unidades mais novas.

A idade mínima para a deposição do Supergrupo Minas pode ser balizada pelo Evento Transamazônico, cujo intervalo de duração foi estimado entre 2125 e 2040 Ma. (Machado \& Noce 1993). Este evento marca uma drástica mudança nas condições plataformais, típicas para a maior parte do Supergrupo Minas. O registro sedimentar deste período é representado pelo Grupo Sabará, por causa de suas caraterísticas de sedimentação sin-orogênica. A idade máxima do Grupo Sabará é balizada por um zircão detrítico com $2124 \pm 4$ Ma. (Machado et al. 1992), idade coincidente com o início do Evento Transamazônico. Devido ao processo de inversão tectônica que marca o início da deposição do Grupo Sabará (Barbosa 1979), é presumível a existência de um hiato entre esta unidade e o Grupo Piracicaba. Tentativamente, admite-se que o topo deste último seja igual ou mais velho que $2150 \mathrm{Ma}$.

O Grupo Sabará é a unidade de maior espessura do Supergrupo Minas, podendo alcancar 3000 a $3500 \mathrm{~m}$ (Dorr 1969). As litologias predominantes são pelitos e grauvacas, ocorrendo também conglomerados, quartzitos, filito grafitoso, tufito e vulcânicas máficas e ácidas (Costa 1961, Barbosa 1968, Dorr 1969, Ferrari 1981). Os conglomerados são portadores, pela primeira vez na seqüência do Supergrupo Minas, de seixos de granito e gnaisse, o que indica importantes modificações da paleogeografia, com soerguimento de novas áreasfonte, aumento da erosão e do gradiente de transporte. Os sedimentos do Grupo Sabará são interpretados como flysch (Barbosa 1968, Dorr 1969). 


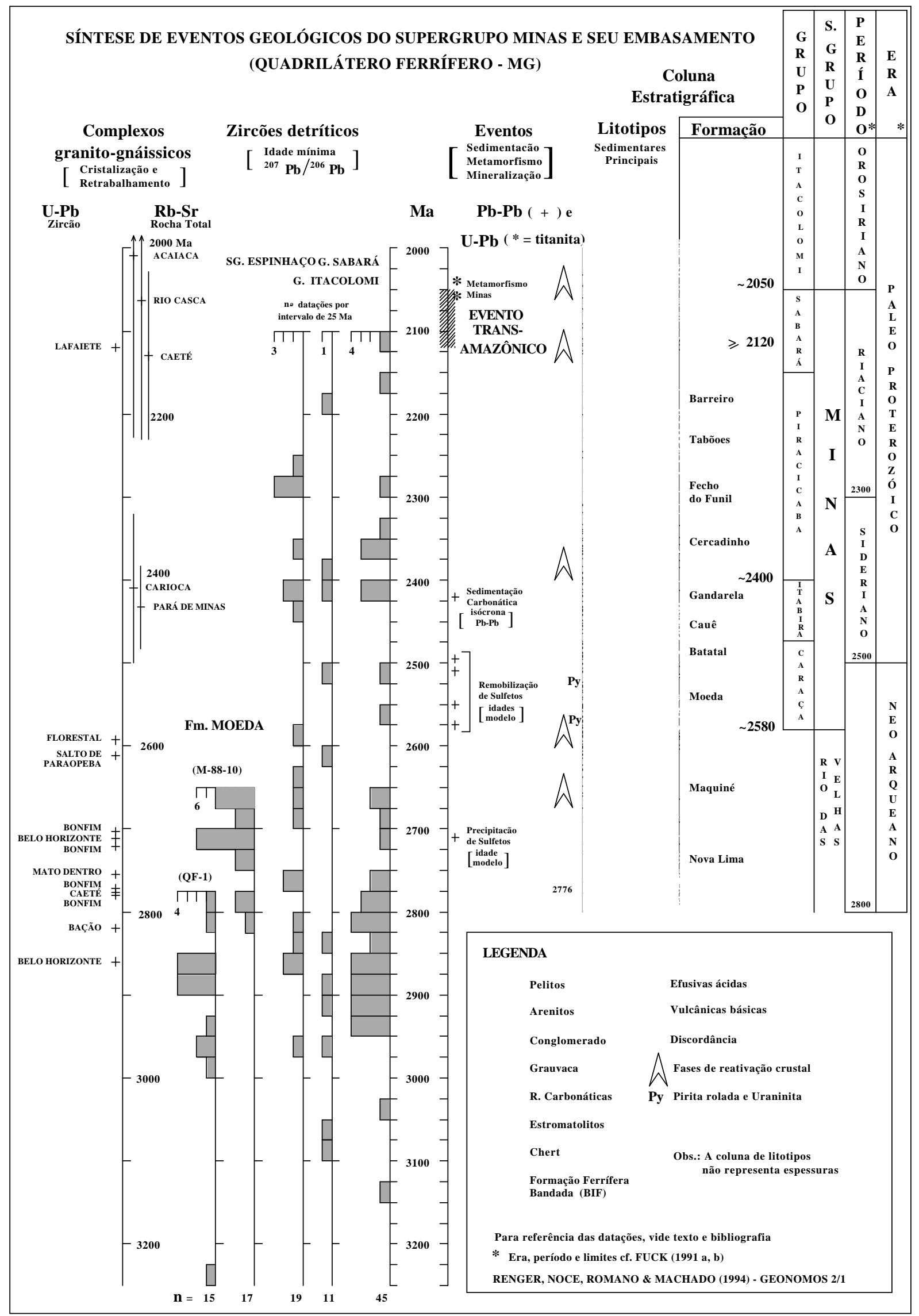

Figura 2: Quadro comparativo dos eventos geológicos do Supergrupo Minas relacionados às datações disponiveis.

Figure 2: Time scale of geological events within the stratigraphic column of the Minas Supergroup, Quadrilátero Ferrífero, Minas Gerais, Brazil. 


\section{COMPARAÇÃO ENTRE O SUPERGRUPO MINAS E TRANSVAAL SEQUENCE (ÁFRICA DO SUL).}

Os limites geocronológicos do Supergrupo Minas (aproximadamente entre 2600 e 2100 Ma.) se comparam aos da Transvaal Sequence da África do Sul, ainda que as dimensões das bacias sejam bastante diferentes. A Transvaal Sequence cobre hoje cerca de $250.000 \mathrm{~km}^{2}$, sua extensão original sendo estimada em $500.000 \mathrm{~km}^{2}$ (ou algo como 400 x $1200 \mathrm{~km}$ ). A extensão atual do Supergrupo Minas, no Quadrilátero Ferrífero, é de aproximadamente 100 x $150 \mathrm{~km}$. Entretanto, além de idades equivalentes, ambas as sequiências exibem colunas litoestratigráficas muito semelhantes, refletindo uma sedimentação essencialmente plataformal iniciada por uma unidade fluvial. (Os nomes das unidades da Transvaal Sequence são citados conforme SACS 1980, Tankard et al. 1982 e Button 1986, vide também Fig. 3).

O intervalo de idade da Transvaal Sequence é balizado pela Ventersdorp Lava (aprox. 2710 Ma.) e pela intrusão do Bushveld Complex a 2050 Ma. no topo. A sua base foi datada em 2557 \pm 49 Ma. nos dolomitos da Schmidtsdrif Formation do Griqualand (método $\mathrm{Pb}$ / $\mathrm{Pb}$, Jahn et al. 1990), que é correlacionável com o Black Reef Quartzite no Transvaal. Mais recentemente, camadas de tufo no Transvaal Dolomite forneceram idade U-Pb em torno de 2600 Ma.. (Barton et al. 1994), que representa a estimativa mais precisa para o início da deposição da sequiência. Galenas do Cambellrand Group (Transvaal Dolomite) apresentam idades $\mathrm{Pb} / \mathrm{Pb}$ consistentes, em torno $2400 \mathrm{Ma}$. (Klein \& Beukes, 1989). Esta idade deve ser interpretada como idade de recristalização, visto que Trendall et al.(1990) indicam $2432 \pm 31$ Ma. como idade da Kuruman Iron Formation, que está sobreposta ao Transvaal Dolomite. Balizando o topo da seqüência existe uma datação do Hekpoort "Basalt" (que na realidade é um andesito) de 2224 \pm 21 Ma. (Rb-Sr em rocha total, Burger \& Coertze 1975).

A comparação das colunas estratigráficas das duas seqüências é mostrada na Figura 3. As grandes discordâncias entre os grupos coincidem grosso modo em idade, e mais ainda em termos sedimentológicos. As discordâncias e a deposição de conglomerados indicam relevo pronunciado e energia de transporte elevada, sendo originadas por soerguimento das áreasfonte e subsidência da bacia ou parte dela. Já os pelitos, e mais ainda as precipitações químicas, indicam períodos de grande estabilidade tectônica da bacia e do hinterland, expressos por taxas reduzidas de aporte de sedimentos.

Na bacia do Transvaal são freqüentes os indícios de uma emersão parcial da seqüência, como por exemplo o karst no topo do Chuniespoort Group, o paleosolo sobre o Hekpoort "Basalt" ou a Dullstroom Lava, extrudida em ambiente terrestre, enquanto que a Machadodorp Lava extrudiu em ambiente submarino com formação de pillow lava (Tankard 1982, Button
1986, vide Figura 3). O paleosolo no topo do Hekpoort Basalt tem espessura média de $5 \mathrm{~m}$; a parte inferior é rica em clorita e na parte superior predomina sericita (Button 1986). Estes fatos indicam um profundo intemperismo, i.e., emersão e hiato de sedimentação sob condições tectônicas estáveis.

A Transvaal Sequence é subdividida em cinco grupos, da base para o topo: Wolkenburg Group, Black Reef Quarzite, Chuniespoort Group, Pretoria Group e Rooiberg Group (Button 1986, Beukes 1986). Apesar do desenvolvimento sedimentológico diferenciado e da nomenclatura diferente no Transvaal e no Griqualand, devido sobretudo à grande distribuição territorial, as colunas estratigráficas estabelecidas para estas duas regiões se correlacionam perfeitamente. Pela idade, composição litológica e posição estratigráfica, o Wolkenburg Group pode ser comparado ao Grupo Maquiné do Quadrilátero Ferrífero. A segunda unidade, o Black Reef Quartzite (Papenfus, 1964) corresponde à Formação Moeda: são unidades siliciclásticas fluviais ou aluvionais, com espessuras variando entre poucos metros e 500 m (Black Reef Quartzite) ou até 1000 m (Formação Moeda), contendo ambas conglomerados portadores de pirita aurífera rolada e uraninita (Frey et al. 1991). Entretanto, em termos sedimentológicos, o conglomerado basal Moeda é melhor comparável ao conglomerado do Ventersdorp Contact Reef, devido à presença de piritas porosas roladas (buck shot pyrite), ao tamanho, composição e classificação dos seixos e também ao sistema de paleodrenagem (Renger et al. 1988, Minter et al 1990). É notável que as duas unidades sejam de idade tardi-neoarqueana, depositadas aproximadamente entre 2600 e 2500 Ma., considerando que o limite entre o Arqueano e o Paleoproterozóico está situado em 2500 Ma. (Fuck 1991a, 1991b).

Os grupos Itabira do Quadrilátero Ferrífero e Chuniespoort do Transvaal são constituidos essencialmente por formação ferrífera bandada $(B I F)$ e dolomito, indicando sedimentação em condições de plataforma estável. O topo dos dois grupos é marcado por discordância erosiva, no caso do Supergrupo Minas, ou angular e erosiva no caso do Transvaal. O itabirito da Formação Cauê tem seu equivalente na Penge (ou Kuruman) Iron Formation (Renger 1970). Ambos os grupos apresentam horizontes manganesíferos associados aos dolomitos. No Quadrilátero Ferrífero o dolomito mais espesso ocorre na capa da formação ferrífera, enquanto que no Transvaal ele ocorre na base da BIF. O ambiente de deposição indica sedimentação em plataforma de águas rasas. Por volta de 2400 Ma. ocorre reativação crustal nas duas bacias, evidenciada pelos conglomerados Rooihoogte no Transvaal e Cercadinho no Quadrilátero Ferrífero.

Acima desta discordância, o Supergrupo Minas continua com o Grupo Piracicaba, que corresponde à parte inferior do Pretoria Group, enquanto que a parte superior deste grupo se correlaciona com o Grupo Sabará. A base do Pretoria Group é formada pelo Rooihoogte (ou Bevetts) Conglomerate, que 
Coluna estratigráfica generalizada do Supergrupo Minas, baseada em seções das Serras de Gandarela e do Curral
Coluna estratigráfica da Transvaal Sequence, África do Sul (modificada segundo Button, 1986)

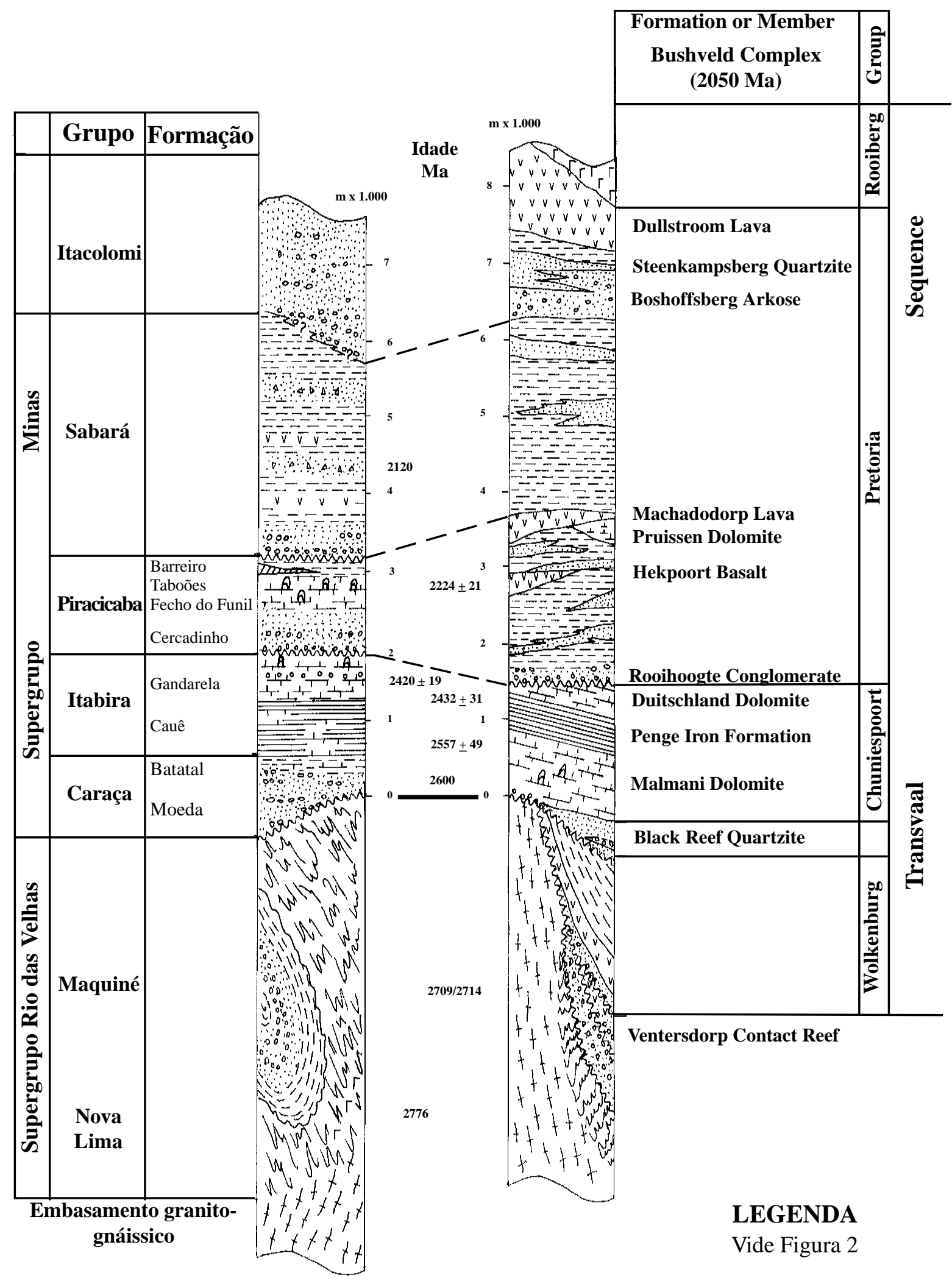

Figura 3: Quadro comparativo das colunas estratigráficas do Supergrupo Minas, Quadrilátero Ferrífero e da Transvaal Sequence, África do Sul.

Figure 3: Comparison of the stratigraphic columns of the Minas Supergroup, Quadrilatero Ferrifero, Minas Gerais, Brazil and the Transvaal Sequence, South Africa. 
corresponde ao conglomerado basal da Formação Cercadinho. Os grupos Piracicaba e Sabará e o Pretoria Group exibem sedimentação clástica a pelítica com termos vulcânicos, estes mais expressivos no Transvaal que no Supergrupo Minas. O Grupo Piracicaba exibe nítida granodecrescência do conglomerado basal Cercadinho até o filito grafitoso da Formação Barreiro, que deve ser interpretado como sedimentação de fechamento de bacia do tipo condensed section. Tanto o Grupo Piracicaba como o Pretoria Group apresentam uma intercalação de dolomito estromatolítico em posição semelhante nas respectivas colunas estratigráficas (Formação Fecho do Funil e Pruissen Dolomite).

A discordância na base do Grupo Sabará pode ser correlacionada, tentativamente, com o evento de extrusão submarina do Machadodorp Lava. A parte superior do Pretoria Group não exibe o caráter de sedimentação sin-sedimentar (tipo flysch) encontrada no Grupo Sabará, devido à ausência de uma fase de dobramento e metamorfismo que corresponderia ao Evento Transamazônico. Na África do Sul, o último evento de pertubação tectônica ocorreu na época da deposição do Chuniespoort Group (2400 Ma.).

Outra coincidência é encontrada no topo das colunas, onde a posição dos membros Boshoffsberg Arkose e Steenkampsberg Quartzite da Transvaal Sequence, com espessura total de cerca de $1000 \mathrm{~m}$, corresponde à do Grupo Itacolomi no Quadrilátero Ferrífero. As intercalações arcosianas dentro do Steenkampsberg Quartzite são interpretados como partes distais de leques fluviais anastomosados (Button 1986).

As coincidências param por aqui. No Quadrilátero Ferrífero a coluna estratigráfica termina com o Grupo Itacolomi, enquanto que no Transvaal existem ainda a Dullstroom Lava e as efusivas ácidas do Rooiberg Group que pertencem ao ciclo intrusivo do Bushveld. Este (infelizmente !) não tem o seu equivalente no Brasil. A idade da intrusão do Bushveld Complex coincide com o fim do Evento Transamazônico, ao redor de $2050 \mathrm{Ma}$..

\section{CONCLUSÕES}

O acervo geocronológico do Quadrilátero Ferrífero permite, com razoável precisão, posicionar temporalmente a sedimentação do Supergrupo Minas entre 2580 Ma. (base da Formação Moeda) e 2050 Ma. (topo do Grupo Sabará). É possível relacionar as fases de sedimentação rudáceas com eventos de movimentação tectônica vertical (extensional), a exemplo das discordâncias basais Moeda, Cercadinho ou compressional do Sabará, aproximadamente datadas em 2580, 2400 e 2150 Ma..

Períodos de sedimentação plataformal com formação de precipitados químicos (das formações Cauê, Gandarela e Fecho do Funil), coincidem com períodos de menor freqüência de datações de zircões detríticos, o que também implica em estabilidade crustal.

A freqüência de datações de zircões detríticos no histograma da amostra QF-1 do quartzito Moeda (figura 2) exibe o mesmo padrão da grauvaca do Grupo Sabará no respectivo intervalo. Isto indica uma mesma áreafonte arqueana para as duas unidades, provavelmente o Complexo Belo Horizonte, demonstrando o caráter autóctone do Supergrupo Minas, pelo menos na sua parte ocidental.

O Grupo Sabará é uma fácies sin-orogênica do Evento Transamazônico, durante o qual o Supergrupo Minas foi dobrado e metamorfisado pela primeira vez. Devido a sua diferenciação faciológica, em relação às formações subjacentes e aliado a uma espessura expressiva (3000 a $3500 \mathrm{~m})$, é proposto o desmembramento da Formação Sabará do Grupo Piracicaba com conseqüente elevação da mesma ao status de Grupo, como já foi sugerido por Barbosa (1968) e Ladeira (1980).

Para uma melhor amarração geocronológica das seqüências sedimentares do Quadrilátero Ferrífero faltam ainda datações adicionais dos quartzitos ou conglomerados do Grupo Maquiné (Sinclinal Vargem do Lima, sopé da Serra do Caraça, sequiências quartzitoconglomeráticas das regiões de Mateus Leme, Pará de Minas e Pitangui), dos quartzitos da Serra do Caraça e da Serra de Ouro Branco, da Formação Cercadinho, da "Facies Santo Antônio" (Congonhas do Campo), entre outros.

Finalmente, uma comparação entre o Supergrupo Minas e a Transvaal Sequence da África do Sul revela perfeita sincronia de idades, litotipos e períodos de reativação crustal nas duas sequiências. Esta reflete, com muita clareza, a evolução atmosférica do globo terrestre durante o Pré-Cambriano. Até o final do Arqueano a atmosfera era não-oxidante, evidenciado pela presença de pirita e uraninita detrítica nos conglomerados Moeda e do Black Reef Quartzite. Por outro lado, a precipitação das enormes quantidades de hematita nas formações ferríferas bandadas (BIF's) das Formações Cauê e da Penge (=Kuruman) Iron Formation documenta uma atmosfera com $\mathrm{O}_{2}$ livre durante o Sideriano (Paleoproterozóico inferior). Este evento foi acompanhado pela precipitação de rochas carbonáticas o que também retirou enorme quantidade de $\mathrm{CO}_{2}$ da água do mar.

\section{AGRADECIMENTOS}

A W.E.L. Minter e F.J. Baars pelas críticas e sugestões em diversas fases da elaboração deste trabalho. 


\section{REFERÊNCIAS BIBLIOGRÁFICAS}

BABINSKI, M.; CHEMALE JR., F.; VAN SCHMUS, W.R. 1991. Geocronologia $\mathrm{Pb} / \mathrm{Pb}$ em rochas carbonáticas do Supergrupo Minas, Quadrilátero Ferrífero, Minas Gerais. In: CONGR. BRAS. GEOQUIM.,3. São Paulo, 1991. Anais...São Paulo, SBGq, vol. 1, p. 628-631.

BABINSKI, M.; CHEMALE JR., F.; VAN SCHMUS, W.R. 1993. A idade das formações ferríferas bandadas do Supergrupo Minas e sua correlação com aquelas da África do Sul e da Austrália. In: SIMP. CRATON SÃO FRANCISCO, 2. Salvador, 1993. Anais...Salvador, SBG-BA,SE/SGM, p. 152-153.

BARBOSA, A.L.M. 1968. Contribuições recentes à geologia do Quadrilátero Ferrífero. SBG-MG, reimpressão (1985): UFMG Inst Geoc., Depto Geol., 44 p.

BARBOSA, A.L.M. 1979. Variação de fácies na Série Minas. Belo Horizonte, SBG-MG. p. 89-100 (Boletim 1).

BARTON, E.S.; ALTERMANN, W.; WILLIANS, I.S.; SMITH, C.B. 1994. U-Pb zircon ages form a banded tuff in the Nouga Formation (Campbell Rand Subgroup), Griqualand West Sequence, South Africa. Geology, in press

BELO DE OLIVEIRA, O.A. \& TEIXEIRA, W. 1990. Evidências de uma tectônica tangencial proterozóica no Quadrilátero Ferrífero, Minas Gerais. In: CONGR. BRAS. GEOL.,36. Natal, 1990. Anais...Natal, SBG, vol. 6, p. 2589-2604

BESANG. C.; EBERLE, W.G.; LAHNER, L.; LENZ, H.; MOLLAT, H.; MÜLlER, P.; PAULSEN, S. 1977. Radiometrische Alterbestimmungen an Gesteinen aus Minas Gerais und Espírito Santo/Brasilien. Geol. Jb., B24:149-179.

BEUKES, N.J. 1986. The Transvaal Sequence in Griqualand West. In: ANHAEUSSER, C.R. \& MASKE, S. eds. Mineral Deposits of Southern Africa, Geol. Soc. of South Africa. vol. 1, p. 819828.

BURGER, A.J. \& COERTZE, F.J. 1975. Age determinations April 1972 to March 1974. Geol. Surv. S.Afr. p. 135-141 (Ann. 10).

BUTTON, A. 1986. The Transvaal Sub-basin of the Transvaal Sequence. In: ANHAEUSSER, C.R. \& MASKE, S.eds. Mineral Deposits of Southern Africa, Geol. Soc. of South Africa. vol. 1, p. 811-817.

CARNEIRO, M.A.; TEIXEIRA, W.; MACHADO, N. 1993. Evolução geológica policíclica de terrenos granito-greenstone do Arqueano Superior do Craton do São Francisco meridional: um exemplo a partir do Complexo Metamórfico Bonfim setentrional. . In: SIMP. CRATON SÃO FRANCISCO, 2. Salvador, 1993. Anais...Salvador, SBG-BA,SE/SGM, p. 70-74

CORDANI, U.G.; KAWASHITA, K.; MÜLLER, G.; QUADE, H. REIMER; V.; ROESER, H. 1980. Interpretação tectônica e petrológica de dados geocronológicos do embasamento na borda sudeste do Quadrilátero Ferrífero. An. Acad. Bras. Ciênc., 52:785-799.

COSTA, M.T.da 1961. Sedimentação e orogênese da Série de Minas Ouro Preto, SICEG. p. 55-61 (Boletim 1)

DELHAL, J. \& DEMAIFFE, D. 1985. U-Pb Archean geochronology of the São Francisco Craton (Eastern Brazil). Rev. Bras. Geoc., 15:55-60.

DORR II, J.V.N. 1969. Physiographic, stratigraphic, and structural development of the Quadrilátero Ferrífero, Minas Gerais, Brazil Washington, US Geol. Surv. 110 p. (Prof. Pap. 641-A).

FENG, R, MACHADO, N.; LUDDEN, J. 1993. Lead geochronology of zircon by Laser Probe-Inductively Coupled Plasma Mas Spectrometry (LP-ICPMS). Geochim. Cosmochim. Acta, 57:3479-3486.

FERRARI, P.G. 1980. Considerações geológicas da faixa bordejante à Serra do Curral entre Ibirité e a Serra da Piedade. Ouro Preto, SICEG. p.80-98 (Boletim 21).

FREY, M.; GERMS, G.J.B.; OBERTHÜR, T.; SAAGER, R. 1991. Textural and composicional characteristics of gold, sulphides and tourmaline in the Black Reef paleoplacers, Transvaal Sequence, South Africa. In: ICAM'91 ( International Congress on Applied Mineralogy), Pretoria, 1991. Pap. 16. 14 p.

FUCK, R. 1991a. Aprovada nova escala de tempo para o PréCambriano. Rev. Bras. Geoc., 21:182-183.

FUCK, R. 1991b. Subdivisão cronométrica do Arqueano: Proposta da Subcomissão de Estratigrafia do Pré-Cambriano. Rev. Bras. Geoc., 21:184-185

HERZ, N. 1970. Gneissic and igneous rocks of the Quadrilátero Ferrífero, Minas Gerais, Brazil. Washington, US Geol. Surv. 58 p. (Prof. Pap. 641-B)

JAHN, B.M.; BERTRAND-SARFATI, J.; MORIN, N.; MACÉ, N. 1990. Direct dating of stromatolitic carbonates from the Schmidtsdrif Formation (Transvaal Dolomite), South Africa, with implications on the age of the Ventersdorp Supergroup. Geology, 18:1211-1214.

KLEIN, C. \& BEUKES, N.J. 1989. Geochemistry and sedimentology of a facies transition from limestone to iron-formation deposition in the early Proterozoic Transvaal Supergroup, South Africa. Econ. Geol., 84:1733-1774.

LADEIRA, E.A. 1980. Metallogenesis of gold at the Morro Velho Mine and in the Nova Lima District, Quadrilátero Ferrífero, Minas Gerais, Brazil. Univ. Western Ontario, unpubl. Ph.D. thesis, 272 p., London, Ontario/Canada

MACHADO, N.; NOCE, C.M.; LADEIRA, E.A.; BELO DE OLIVEIRA, O.A. 1992. U-Pb geochronology of Archean magmatism and Proterozoic metamorphism in the Quadrilátero Ferrífero, southern São Francisco Craton, Brazil. Geol. Soc. Amer. Bull., 104:1221-1227.

MACHADO, N. \& CARNEIRO, M.A. 1992. U-Pb evidence of late Archean tectono-thermal activity in the southern São Francisco shield, Brazil. Can. J. Earth Sci. 29:2341-2346.

MACHADO, N. \& NOCE, C.M. 1993. A evolução do Setor Sul do Cráton São Francisco entre 3,1 $20,5 \mathrm{Ga}$ baseada em geocronologia U-Pb. In: SIMP. CRATON SÃO FRANCISCO, 2. Salvador, 1993. Anais...Salvador, SBG-BA, SE/SBG. p.100102.

MACHADO,N.; NOCE, C.M.; FENG, R. 1993. Idades ${ }^{207} \mathrm{~Pb} /{ }^{206} \mathrm{~Pb}$ de zircões detríticos de rochas metassedimentares da região do Quadrilátero Ferrífero, sul do Cráton do São Francisco: Considerações sobre áreas-fonte e idades de sedimentação. In: SIMP. CRATON SÃO FRANCISCO, 2. Salvador, 1993. Anais...Salvador, SBG-BA,SE/SGM, p. 149-151.

MINTER, W.E.L.; RENGER, F.E.; SIEGERS, A. 1990. Early Proterozoic gold placers of the Moeda Formation within the Gandarela Syncline, Minas Gerais, Brazil. Econ. Geol., 85:943951.

NOCE, C.M. 1994. Geocronologia dos eventos de magmatismo, sedimentação e metamorfismo no Quadrilátero Ferrífero, Minas Gerais. (Tese de Doutorado, USP).em preparação.

NOCE, C.M.; , LADEIRA E.A.; PINHEIRO, S. O.; FRANCA, C. R. 1992 A sequência vulcano-sedimentar do Grupo Nova Lima na região de Piedade do Paraopeba, borda oeste do Quadrilátero Ferriféro, Minas Gerais. Rev. Bras. Geoc., 22:(no prelo).

PAPENFUS, J.A. 1964. The Black Reef Series within the Witwatersrand Basin with special reference to its occurrence at Government Gold Mining areas. In: HAUGHTON, S.H. ed. The geology of some ore deposits of South Africa. Geol. Soc. of South Africa. vol. 1, p. 191-218.

RAMDOHR, P. 1960. Die Erzmineralien und ihre Verwachsungen. Berlin (Akademie Verlag). 1089p.

RENGER, F.E. 1970. Fazies und Magmatismus der Minas-Serie in der südlichen Serra do Espinhaço, Minas Gerais, Brasilien. Geol. Rundsch., 59:1253-1292.

RENGER, F.E.; SILVA, R.M.P.; SUCKAU, V.E. 1988. Ouro nos conglomerados da Formação Moeda, sinclinal de Gandarela, Quadrilátero Ferriféro, Minas Gerais. In: CONGR. BRAS. GEOL.,35. Belém, 1988. Anais...Belém, SBG, v. 1, p. 44-57

ROMANO, A.W. 1989. Évolution tectonique de la région nord-ouest du Quadrilatère Ferrifère - Minas Gerais - Brésil (Géochronologie du socle - Aspects géochimiques et pétrographiques des Supergroupes Rio das Velhas e Minas). (Tese de doutorado, Univ. Nancy I). 259 p.

SACS (SOUTH AFRICAN COMMITTEE FOR STRATIGRAPHY), 1980. Stratigraphy of South Africa, Handbook 8, Part 1: (Comp. L.E. Kent), Lithostratigraphy of the Republic of South Africa, South West Africa/Namibia and the Republics of Bophuthatswana, Transkei and Venda: Handb. Geol. Surv. South Africa., 8, 690p. 
TANKARD, A.J.; JACKSON, M.P.A.; ERIKSSON, K.A.; HOBDAY, D.K.; HUNTER, D.R \& MINTER, W.E.L. 1982. Crustal evolution of South Africa, 3.8 billion years of earth history. New York - Heidelberg - Berlin (Springer Verlag) 523 p.

TEIXEIRA, W. 1985. A evolução geotectônica da porção meridional do Craton do São Francisco, com base em interpretações geocronológicas. (Tese de Doutorado, USP). 207 p.

TEIXEIRA, W.; JORDT-EVANGELISTA, H.; KAWASHITA, K.; TAYLOR, P.N. 1987. Complexo granulítico de Acaiaca: idade, petrogênese e implicações tectônicas. Belo Horizonte, SBG-MG. p. 58-71 (Boletim 7).

TEIXEIRA, W. \& FIGUEIREDO, M.C.H. 1991. An outline of early Proterozoic crustal evolution in the São Francisco craton, Brazil. Precambr. Res., 53:1-22.

THORPE, R.I.; CUMMING, G.L.; KRSTIC, D. 1984: Lead isotope evidence regarding age of gold deposits in the Nova Lima
District, Minas Gerais, Brazil. Rev. Bras. Geoc., 14:147-152.

TRENDALL, A.F.; COMPSTON, W.; WILLIAMS, I.S.; ARMSTRONG, R.A.; ARNDT, N.T.; MCNAUGHTON, N.J.; NELSON, D.R.; BEUKES, N.J.; LAETER, J.R.; RETIEF, E.A.; THORNE, A.M. 1990. Precise zircon U-Pb chronological comparison of the Kapvaal and Pilbara Cratons between about 3.1 and 2.4 Ga. In: INT. ARCHEAN SYMP., 3. Perth, 1991. Abstracts...Perth, Geoconferences, p. 81-83

VILLAÇA, J.N. 1981. Algums aspectos sedimentares da Formação Moeda. Belo Horizonte, SBG-MG. p. 93-137 (Boletim 2).

WALLACE, R.M. 1965. Geology and mineral resources of the Pico do Itabirito district, Minas Gerais, Brazil. Washington, US Geol. Surv. 68 p. (Prof. Pap. 341-F).

WALRAVEN, F.; ARMSTRONG, R.A.; KRUGER, F.J. 1990. A chronostratigraphic framework for the north-central Kaapvaal craton, the Bushveld Complex and the Vredefort Structure. Tectonophysics, 171:23-41. 